\title{
KASP: A Cognitive-Affective Methodology for Designing Serious Learning Games
}

\author{
Tahiri Najoua, El Alami Mohamed \\ National School of Applied Sciences of Tangier \\ Abdelmalek Essaadi University \\ Tangier, Morocco
}

\begin{abstract}
Many research studies agree on the existence of a close link between emotion and cognition. Actually, much research has demonstrated that students with learning disabilities (LD) experience emotional distress related to their difficulties. In this regard, this article proposes a new methodology of designing intelligent games called KASP Methodology, it's a new approach applied to the serious games (SGs) design field. It includes new decisive factors for designing SGs for children with LD.

The proposed methodology is based on four pillars which are: Knowledge, Affect, Sensory and Pedagogy and it aims helping designers of serious games for building suitable serious learning games for children with LD taking into account the cognitive and emotional aspects of the child learner in order to improve his learning rhythm and foster his emotional state related to learning in a playful and interactive environment.
\end{abstract}

Keywords-Methodology; Affective Computing; Serious Games; Learning Disabilities; Game Design; Knowledge; Pedagogy

\section{INTRODUCTION}

Although the term learning disability has been used since 1962, there is no universally accepted and consistent definition. The current descriptions and definitions of learning disabilities are found in the World Health Organization Disability Document, in legislation and policy related to education, disability issues, psychology, medicine and human rights.

According to the World Health Organization, the learning disability is a medical term that refers to a permanent disorder of neurological origin. A learning disability is an impairment of one or more neuropsychological functions, which disrupts the acquisition, comprehension, use and processing of verbal or nonverbal information.

Many international organizations have come up with their own definitions of learning disabilities with different visions. The NIH(National Institutes of Health), for example, defines LDs as disorders that affect the ability to understand or use spoken or written language, to make mathematical calculations, to coordinate movements or to attract attention. However, learning disabilities occur in young children, disorders are generally not recognized until the child reaches school age.

In addition, the National Advisory Committee on Children with Disabilities (CNAMC) developed in 1967 a widely cited definition of learning disabilities: Specific Learning Disorder means a disorder in one or more of the basic psychological processes involved in the comprehension or use of spoken or written language, which can manifest itself in an imperfect ability to listen, think, speak, read, write, spell, or do mathematical calculations. The term includes conditions such as perceptual disabilities, brain injury, minimal brain dysfunction, dyslexia, and developmental aphasia.

In general, learning disabilities are neurological treatment problems. These treatment problems can interfere with learning basic skills such as reading, writing and / or mathematics. They can also interfere with higher-level skills such as organization, time planning, abstract reasoning, long-term or short-term memory, and attention.

In order to improve the learning potential of children with $\mathrm{LD}$, we propose in this article a new approach to design serious games with educational interest for the benefit of children with learning disabilities.

A serious game is a tool that aims to train more than to be entertained. The serious games market has, and continues to be, an undeniable popularity in various fields such as education, health, advertising, politics, etc. The synthetic definition of a Serious Game is the one proposed by video game designers Michael and Chen [1]: Any game in which education (in its various forms) in the primary goal, rather than entertainment.

Indeed, a Serious Game is characterized by the presence of a dimension playful and a serious dimension explicitly desired by its designer [2]. However, a Learning Game is a computer application that uses fun springs to catalyze the attention of learners and facilitate their learning. It has explicit educational goals and can be used for training at all levels [3].

Moreover, the main objective of the design methodology proposed in this article is to allow the implementation of serious learning games tailored to take into account several specifications not only cognitive but also the emotional character of the learner by benefiting from the advantages of affective computing in an educational approach.

In this perspective, the article first presents the potential of Game-based learning and an overview of learning disabilities, their symptoms and types. Secondly, it establishes the difference between a serious game and a learning game. Then, it draws up a literature review related to methods of designing serious games. Fourth, it introduces a new methodology of designing serious learning games for children with learning disabilities. Finally, it presents a discussion of the results obtained as well as the strengths and limitations of the proposed methodology.

\section{Game-BASEd LeARning Potential}

Learning is an active process of combining new information with old ones, a process of building networks and 
relationships between and in the fields of knowledge [4].

Despite the fact that learning theories ignored the importance of affective processes in learning and focused on cognitive aspects. Many specialists in psychology (Wilhem Wundt) and pedagogy (Montessori) have proved the close relationship between emotion and learning. Schutz et al.[5] defines emotions as ways of being and as holistic episodes that include physiological, psychological and behavioral aspects.

In addition, the neuroscientist Damasio explains how minds emerge from emotions and feelings, his insight confirms the essential role of emotions in cognition: Recent advances in the neuroscience of emotions highlight the links between cognitive and emotional functions that have the potential to revolutionize our understanding of learning in the context of schools [4].

In this regard, Hascher proposes a new framework for the dynamic interaction of learning and emotion in the school context where she stresses the importance of integrating the two cognitive and affective approaches, she experiences that the emotion plays a role parallel to that of cognition in any learning environment [6].

As a result, the links between emotion and learning are bidirectional and interdependent, because emotions influence thoughts, and infer new emotions. Therefore, building the selfesteem, interest, and intrinsic value of education that boosts enthusiasm for learning and reduces the negative emotions of the learner will improve his learning rhythm.

\section{LEARNING DISABILITIES}

A dysfunction in the neurological treatment of the child leads to the onset of learning disabilities, they are disabilities that disrupt as well as academic performance as daily interactions such as relationships with peers and that last a lifetime. Its a neurological disorder that comes from a difference in how a person's brain is wired.

Children with learning disabilities may have difficulty reading, writing, spelling, reasoning and organizing information, they are intelligent or smarter than their peers. So they need unconventional learning.

Learning disabilities appear as developmental delays or as difficulties in the aspects of functioning listed below:

- $\quad$ Limited attention capacity;

- Bad memory;

- Difficulty following directions;

- Inability to distinguish between / among letters, numbers or sounds; Bad reading and / or writing skills;

- Hand-eye coordination issues; poorly coordinated;

- Difficulties with sequencing, and / or disorganization and other sensory difficulties;

Relatively to these signs, each child displays one or more symptoms that indicate the type of disorder the child is suffering from as shown in Fig. 1. In fact, learning disabilities include:

- Dyslexia or reading difficulties: Dyslexic children have difficulty reading correctly and fluently because

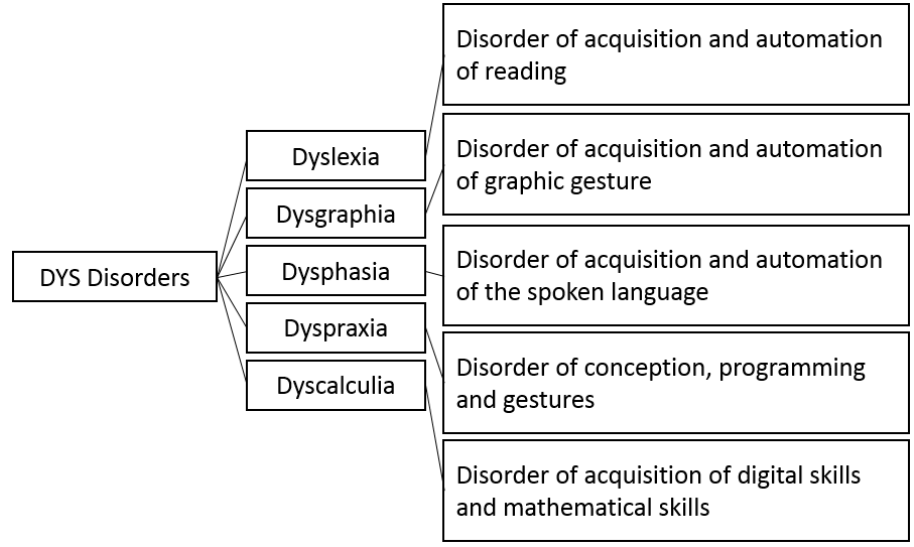

Fig. 1. Dys disorders

they have a bad association between graphemes (written signs) and phonemes (sounds). They may also have problems with reading comprehension, spelling, and writing;

- Dyspraxia: it is often associated with visio-spatial deficiencies or difficulties in the muscular control which causes problems of coordination as well as disturbances of organization of the gaze which disturb the apprehension of the environment by the child;

- Dysgraphia: it refers to the physical difficulty forming words and letters. A dysgraphic child may have problems, including unreadable writing, irregular spacing, poor space planning on paper, bad spelling, and difficulty composing, writing, and thinking at the same time;

- Dyscalculia: Children with this type of learning disability may have a poor understanding of mathematical symbols, have difficulty remembering and organizing numbers, have trouble telling time, or have trouble counting;

- Dysphasia: it comes in various forms relating to difficulties in expressing oneself, or understanding what is said. Dysphasia affects more than one component of language in a variable way;

It is important to realize that learning disabilities are distinct from learning difficulties because these are temporary barriers closely related to socio-emotional conditions. Once the elements in question are eliminated, the person usually finds a normal learning rhythm. Unlike learning disabilities that are persistent and permanent and result from impairments in one or more learning-related psychological processes, in combination with normally average skills essential to thinking and reasoning.

\section{SERIOUS GAMES AND LEARNing GAMES}

Despite the many treatises published on the term 'game', researchers still find it elusive. Its a structured, rules-based activity, usually done for fun. However, games can have another purpose other than fun, and can position themselves as a teaching tool bringing together playfulness and learning at a 
time. Also, Gaussot [7] describes the game as an educational means contributing to the emotional, sensory, motor, cognitive, intellectual and social development of the individual.

Golinkoff et al. [8] say that Play = Learn. As children move from sandbox to classroom, play should be the cornerstone of their education. The research is clear: Game pedagogy supports socio-affective and academic forces while instilling a love of learning. Many literature reviews were conducted on learning games, Abdul Jabbar and Felicia[9] established a study to discover how the design of play-based activities influences engagement and learning. They developed a set of general recommendations for the educational design of Game-Based Learning.

It should be mentioned that the word serious game exists since the 1960s when Clark Abt baptized his book Serious Game, where he explores the ways in which games can be used to educate and inform as well as to provide pleasure, he proposes its own definition: have an explicit and thoughtful educational purpose and are not intended to be played primarily for fun. This does not mean that serious games are not or should not be entertaining [10].

As for Egenfeldt-Nielsen et al.[11], they believe that Serious Games as digital games and equipment with a program of educational design and beyond entertainment. To the extent that learning is characterized by being an active, constructive, self-directed and emotional process.

Therefore serious games have the potential to support this sequence, as they present aspects of motivation, accuracy, challenge as well as information on request and just in time. Through play, the child-learner fully engages in training and becomes master of his learning in defiance of traditional passive learning.

\section{Design Methodologies of Serious Games: LITTERATURE REVIEW}

There are several methods of designing educational games, which vary according to the context used, the objectives to be achieved and the target audience. In the following a brief presentation of serious educational game design methods.

Before discovering the different methods of designing a Serious Game, first defining the term 'Game Design'. According to Salen and Zimmerman [12]: it is a process by which a designer creates a game, intended to be used by a player, so that a game experience is born. Alvarez et al.[2] defines it as: The process of inventing in a broader sense, game design refers to the idea behind a game.

Since a Game Design is a process, it means a continuous sequence of operations or activities leading to a predefined goal. Consequently, its necessarily a collaboration between several actors, hence the notion of 'collaborative'design method. The work that has been done to find a generic approach to design serious learning games is based on three pillars, such as the one proposed by Lloyd Buck [13], which confirms that these components must be attractive, responsive to objectives and specific educational applications.

Paquette et al. [14] proposes a learning systems engineering method called MISA, which aims to apply cognitive science principles to the field of instructional design. It is a very robust approach because it implements the most rigorous teaching practices. In the same vein, the Swedish Tele-Pedagogical Knowledge Center (1993) has created its own design method for developing about twenty standard documents describing all parts of the training. In addition, KTM Advance, a leading digital professional training company, offers an industrial design model specific to Serious Games [15].

Several approaches of designing serious games are inspired by pedagogical engineering, the DODDEL model (DocumentOriented Design and Development of Experiential Learning) proposed by Mcmahon [16], it has key features in that it promotes a theoretically inclusive approach to learning, a focus on game elements and an emphasis on documentation to provide the rigour necessary to be used as part of a broader project management model.

Furthermore, Marfisi-Schottman suggests a collaboration platform that offers a methodology and adapted tools to guide the various actors that participate in a Learning Games conception.

Although there is a plurality of methods that have a certain maturity in the field of e-learning, no approach concerns serious learning games for children with learning disabilities and which affect not only their ability to learning but also their interaction with their environment. The choice of educational activities related to this specific type of games should be carefully designed to encourage the learner to be a central player in the learning cycle.

We note that the different design methodologies of serious games previously cited all converge towards an approach that is based on the cognitive aspect of the learner where some rely on pedagogical engineering, others propose a collaboration between designers. However, it is necessary to mention that the design methodology of intelligent serious games must support the evolution of knowledge and involve the players profile in all stages of the design.

Indeed, the affective aspect is always isolated, although the factor related to the emotion occupies a crucial place in any process of learning, also the audio-visual and kinesthetic specifications are ignored despite their importance in the engagement of the player in any serious learning game.

On the other hand, the learning style is also considered as a major factor in the design of serious games because it makes it possible to adapt the proposed system to the preferences of the learner. It is defined by distinctive cognitive, affective, physiological and sociological behaviors; these behaviors serve as relatively stable indicators of how an individual perceives and processes information, interacts and responds to the learning environment [17].

Recommending serious learning games, according to the kind that best suits the characteristics of a learner, could improve learners motivation and lead to a better learning experience [18]. As a result, the adaptation of learning systems to learning styles and gamification seems to be a promising concept. 


\section{Diagnostic model}

$\sqrt{1}$

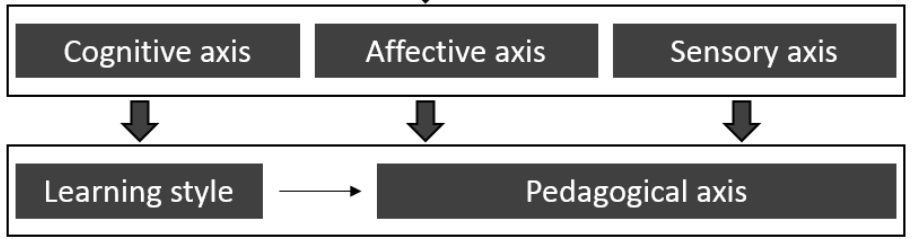

Fig. 2. The components of KASP methodology

\section{Vi. Design Methodology Diagnostic-Centered of SERIOUS GAME FOR CHILDREN WITH LEARNING DISABILITIES}

In this regard, the authors propose a new methodology of designing serious games well adapted to the cognitive and affective needs of children with LD. Conceptualizing an intelligent game to develop the behavior, knowledge and reflections of a child presents a challenge especially when it comes to a player with learning disabilities taking into account basic criteria such as: the pedagogical environment, affective and cognitive reactions of the learner, the learning context, and also the learners profile.

In the interest of developing an effective intervention plan that will help children with LD to learn better, a first step of screening is therefore required, which is to gather information from various sources: parents, teachers, and speech therapists, so to determine the educational needs of the child and then indicate the appropriate educational strategies taking into account cognitive, affective and physical factors.

This early detection requires the coordination of all people revolving around the child, in order to formulate diagnostic hypotheses to improve the capacities considered to be deficient.

The next step is that of the diagnosis conducted by a clinical team, it consists of a list of tests to specify: personal history of the child, several examinations of type: psychological, cognitive, and somatic including a sensory examination.

In this perspective, we propose to use a multi agent platform called DIAUTIS [19] that offers a wide and variable collection of tests, including computerized interviews with parents, using sensors to analyze the interaction of the child through the monitoring of ocular activity, the observation of movements, as well as the interpretation of vocal responses.

Through these sensors, the DIAUTIS system is able to deduce the emotional state of the child diagnosed through its multi agent structure scalable and flexible.

The results of the tests performed via DIAUTIS will be analyzed in order to deduce the basic skills of the child by developing a deliverable containing five specifications: motor, behavioral, cognitive, socio-emotional, and sensory. An intelligent system for classifying these specifications is put in place using the techniques of Machine Learning that will give rise to the type of disorder that the diagnosed child suffers.

Machine learning is a domain derived from artificial intelligence that makes machines capable of learning, in simple terms, is the ability to identify models that can analyze larger and more complex data and to obtain faster and more accurate results, even on a very large scale, and to make decisions with minimal human intervention. The renewed interest in Machine Learning is due to the efficiency of the algorithms it understands in terms of accuracy and speed.

In this case, the authors propose to use one of the famous supervised type algorithms, SVM (Support Vector Machine), on the set of specifications selected from the diagnosis, in order to obtain the type of the disorder of the child in question thanks to the intelligent classifier. The proposed methodology consists of four axes, each axis includes an iterative process allowing its development through the experts intervention:

- The knowledge axis (KA): distinguishes different types of knowledge and links, which prepares the choice of educational activities.

At this level, the serious game is assimilated to knowledge-based system, where unity 'knowledge 'is the key element since through this, we take cognitive deficits of the child with LD.

Each concept is represented hierarchically in the brain of the child, at each new experience, the model of knowledge undergoes some modifications. So the first goal is to acquire the model corresponding to a given concept, to extract knowledge.

- The affective axis (AA): the omnipresence of the emotional aspect is essential, because the emotional state of the child can significantly change the pace of learning.

This axis aims to raise the difficulties related to emotion and social interactions in order to develop them implicitly via the games on offer.

- The sensory axis (SA): it allows to specify the auditory, visual and kinesthetic parameters of the child to adapt the choice of the game to the player, the choice of interfaces, colors and sounds is done at this level.

- The pedagogical axis (PA): the objective through this one is to specify the basic pillars for learning from an institutional point of view, by making possible a mental activity of the learner in a learning situation.

The knowledge, emotional and sensory axes are derived from the diagnostic model, and the learner style and the pedagogical axis are developed by pedagogical experts by analyzing the three axes previously mentioned as presented in Fig. 2.

The KASP methodology is based on four pillars which are: Knowledge, Affect, Sensory and Pedagogy, as seen in Fig. 3 , and it contains three main phases which are:

1) Preliminary analysis (PAP)

2) Development of conception phase (DCP) which is a prototyped cyclic process composed of three stages as follows:

a) Elaboration of the conceptual architecture (CA)

b) Development of the prototype (PD)

c) Test and validation stage (TE)

3) Deployment phase (DP) 


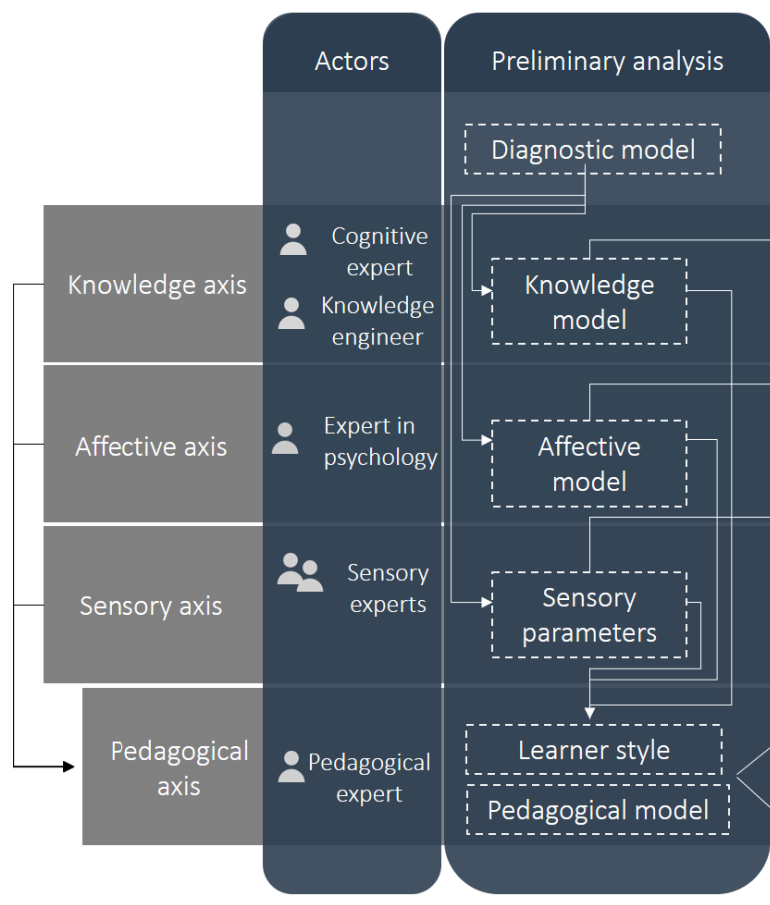

Fig. 3. KASP methodology

In the first phase PAP: It allows a better understanding of the system based on the understanding and the structuring of the needs.

- For the KA: An exploitation of the diagnostic model by the cognitive expert is implemented to clarify the deficits relating to the childs knowledge.

A good expression of the childs cognitive needs will allow a better choose of the pedagogical activities in order to correct any imperfection of the executive functions (EF), which are the cognitive skills necessary to control ones thoughts, emotions and actions.

- For the AA: Also the EF occupy a central place in the psychological development of the child, from where an intervention of the expert in psychology of the children is necessary in order to draw the emotional specifications relating to the identified disorder.

- For the SA: Three other experts come into play, hearing, vision and kinesthetic, the goal is to analyze the diagnostic model to specify if the child suffers from a hearing, visual or kinesthetic abnormality in order to carry out a needs analysis sensory appropriate to the child.

- For the PA: following the deliverables of the KA, AA and SA, the pedagogical expert determines the pedagogical objectives of the game to be chosen, it also describes the path that the learner must take to acquire the knowledge.

In the second phase DCP: The goal is to grasp the operational requirements, thus to focus on the main features and functions to be provided. The stage is composed of three iterative sub-steps, starting with the development of the conceptual architecture:

- For the KA: the cognitive expert elaborates the set of mental models of the child, which are cognitive representations illustrating the way in which the child perceives a given concept, in other words a mental model is a form of analogical representation of knowledge. Any inadequacy of the mental model is followed by a state of disorientation.

- For the AA: the psychological expert prepares the mental models of the childs emotional states in order to act in the direction to regulate the emotions that influence his learning in a destructive way.

- For the SA: in terms of sensory, the experts specify the audio-visual- kinesthetic parameters to take into consideration when elaborating the serious games.

- For the PA: the pedagogical expert defines the pedagogical scenarios which are the set of learning situations aiming at the appropriation of a precise set of knowledge taking cognizance of the cognitive and affective mental models as well as the sensory parameters.

Relative to the prototyping step, the four axes provide prototype deliverables for test and validation by the experts in each axis. The operation is repeated as and when to obtain the best prototype in order to move to the deployment phase. For the third step (Test and validation): it enables to identify 
the problems, to analyze concretely their causes and to propose solutions that are implemented in the future prototype.

In the third phase DP: Several actors intervene at this stage, namely: study and development engineers, graphic designer, expert in the design in order to implement a software prototype answering the needs and the conceptual architectures expressed in the steps PAP and DCP. The made prototypes are an implementation of the educational scenarios in a playful environment.

In brief, The KASP methodology begins with a preliminary analysis studying the diagnostic model delivered by the clinical team (as can be seen in Fig. 4).

In a first step, three models are concluded: knowledge, emotional, pedagogical, as well as a deliverable concerning the sensory specifications of the diagnosed child. At this level the objectives to be achieved are studied.

In a second step, the development of the conceptual architecture is set up by developing the mental models relating to knowledge, emotions, as well as the orientation of the pedagogical scenarios based on the learning style found, these orientations obviously take into account auditory, visual and kinesthetic specifications.

In a third step called prototyping, we proceed to the generation of prototypes of knowledge, emotional, and the generation of pedagogical scenarios, in other words it is at this level that the design of the scenes of the proposed game are built.

In the fourth step, the experts intervene to test and validate the prototype stage in order to guarantee a design adapted to the purposes set in the first step. These last three steps enter a loop to refine the result before moving to the deployment stage, in which the technical environment is set up.

KASP methodology serves the strengths of artificial intelligence that lies in the intelligent management of the knowledge collected, more precisely in the representation of knowledge through semantic networks [20] formed by several elements in interrelation, these elements are: nodes, links, and the set of operations constituting the reasoning mechanisms.

The semantic networks make it possible to structure the knowledge base thanks to the organizational axes (generalization, partition, aggregation). More precisely, the authors suggest using learning networks that build or extend their representations by acquiring knowledge from examples. New knowledge can change the old network by adding and removing nodes and arcs or by modifying numerical values, called weights, associated with nodes and arcs [21].

In addition, identifying the emotion of the learner through affective computing [22] is one of the strong points of the KASP methodology. Indeed, emotional learning is concerned with how learners feel while they are learning, as well as the way in which learning experiences are internalized so that they can guide the attitudes, opinions and behavior of learners [23].

Multiple research studies related to the integration of affective computing in intelligent learning systems (ILS) have been put in place, we quote that of de Arriaga et al.[24] presenting the implementation of a factory of ad hoc agents

\begin{tabular}{|l|l|}
\hline - $\begin{array}{l}\text { Clinical history and interview } \\
\text { - Physical exam }\end{array}$ & 1- Information gathering \\
\cline { 2 - 2 } - Medical history & \\
\cline { 2 - 2 } - Diagnosis teting & 2-Information integration \\
\cline { 2 - 2 } - Classroom observation & 3-Information interpretation \\
\cline { 2 - 2 } - Test on langauge skills & \\
\cline { 2 - 2 } - Test on basic skills & 4- Communication of the diagnosis \\
\hline
\end{tabular}

Fig. 4. Prior medical and psychomotor diagnosis

named NEOCAMPUS2 for the development of ILS, the latter is characterized by the co-existence of pedagogical, cognitive and affective agents.

In addition, the intelligent management of knowledge on the different cognitive, affective and pedagogical levels will make it possible to deduce the learning style of the learner. Providing learners with learning resources and activities tailored to their preferences and learning styles increases their satisfaction and improves learning performance.

Theoretically, there are several models of learning styles [25]; [26]. Extraction and follow-up of the learners learning style can be done through neural networks [27]. According to Simon[28], the neural network is defined asa massively parallel distributed processor consisting of simple processing units, which has a natural propensity to store experiential knowledge and make it usable.

The proposed methodology is diagnostic centered because it exploits the knowledge derived from a diagnostic model established by a clinical team. Although diagnosing a learning disability is not always easy, even if the symptoms seem clear. It is important that the child is tested and evaluated by qualified professionals. Recognizing that the diagnostic criteria for identifying different learning disabilities have been established by the American Psychiatric Association (DSM-IVTR, 2000) and the World Health Organization (ICD-10, 2003). These criteria are internationally recognized by the scientific and medical authorities.

The diagnosis may sound like a medical term; and, in some ways, it is. It is primarily administered by a health professional and is often based on the medical symptoms of a child. Sometimes, several professionals coordinate team services to obtain an accurate diagnosis. They can ask for comments from the childs teachers and parents.

To carry out a diagnosis of learning disabilities, we must start from the analysis of basic skills, which are the basic skills necessary for the child to build and perform the correct behaviors of learning to read, write and calculate. Without the proper organization of these skills in terms of perceptual, linguistic and psychomotor expression, the child will not attain the development that allows him to acquire the knowledge and skills of the different learning.

For this, the diagnostic model includes 5 specifications (see Fig. 5) from a medical and technical diagnosis of high level, its aspects are as follows: 


\section{A. Motor Specifications:}

Motor impairment can also occur for some children with LD and influence their academic performance and activities in their daily lives. The following parameters are the subject of the model motricity diagnosis:

- Inability to coordinate both sides of the body

- Difficulty following directions

- Difficulty controlling pencils, scissors, or coloring in lines

- Difficulty with buttons, zippers, learn to tie shoes

- $\quad$ Bad writing

- Difficulty using clay to make balls

- Difficulty feeding yourself with spoon and fork

- Move your head

- Difficulty discriminating shapes, texture size only by touch

\section{B. Behavioral specifications:}

Children with LD report being more disruptive, less cooperative, insensitive, and more tactical in school or family environments, always seeking to attract attention, indicating a disruption in behavior. The diagnostic model includes the behavioral indicators below:

- Clownerie

- Complete the tasks as quickly as possible "just to finish"

- Reject, leave an activity or task

- Not wanting to go to school

- To complain about the teacher

- To say that the work is too hard

- $\quad$ Say negative things about your academic abilities such as: "I'm stupid"

- $\quad$ Refuse to work at school or to resist homework

- Refuse to follow the instructions of the teacher to be sent from the room

- Use other delay tactics to avoid a mission

- Change places frequently

\section{Cognitive specifications:}

Historically, constructivist theories originated with the work of Jean Piaget, a researcher who has studied how children's intelligence progresses with their age, and how they progress intellectually into adulthood. Even if it is strongly criticized, Piaget's theory still remains a reference for the first apprenticeships. For the diagnostic model, we are interested in two major aspects of the child's cognitive development which are the spatio-temporal aspect and the pedagogical aspect. Spatio-temporal deficit:

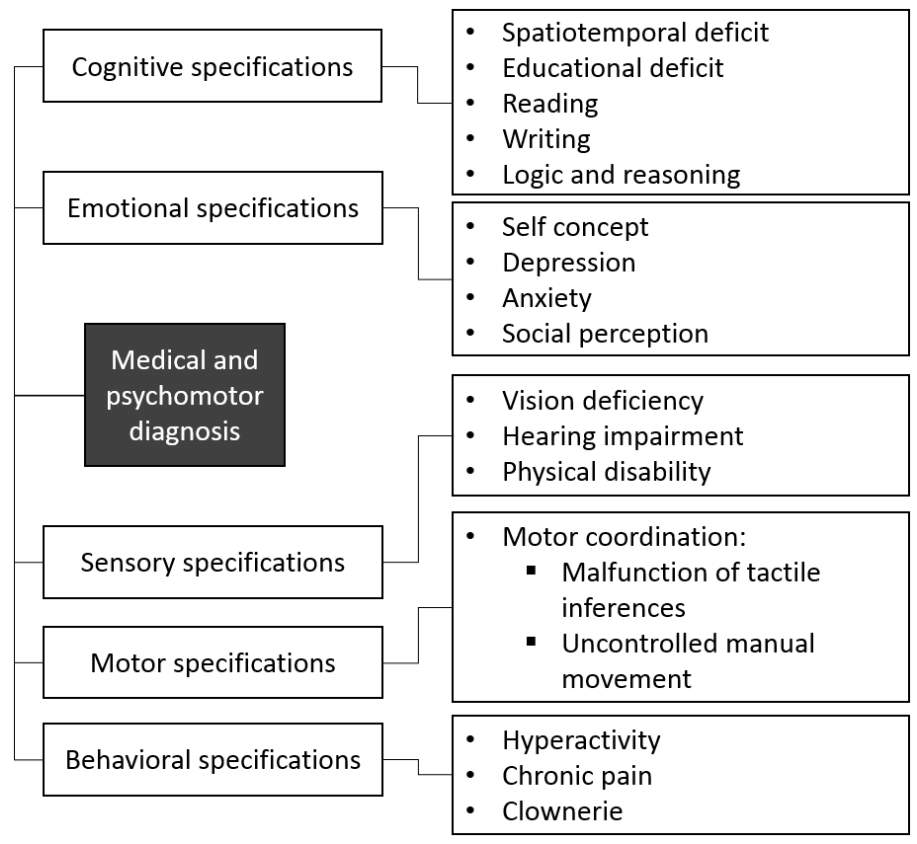

Fig. 5. Diagnostic model specifications

When there is a kind of anomaly in visual or auditory perception and spatio-temporal structuring, this manifests itself in the acquisition and expression of the signs used in basic learning, so it is essential to analyze the development and operation of these levels.

\section{Educational deficit:}

A psycho-educational battery of formal and informal tests is used to determine patterns of strength and weakness in relation to intellectual ability. This battery will provide answers to the following:

- Reading and listening:

- Reading aloud

- The understanding of certain words

- The ability to understand what is said

- The ability to follow a short story and memorize it

- Is the child able to answer an interview?

- Spelling and writing:
- Writing ability
- The writing order
- Capitalization and punctuation

- Math and logic:

- The ability to differentiate symbols and operations

- Does the child consider the number and its inverse in the same way?

- The ability to count coins, bills and give change

- Is the child able to find the duration, start time and end time? 


\section{Socio-emotional specifications:}

Although communication plays a preponderant role in the social life of the child because it is a valuable tool for transmitting values and bases. Children with learning disabilities find it difficult to interpret social cues which influence their ability to adapt their behaviors or even exhibit inappropriate social behaviors.

As a result, negative interactions with others have been linked to the neglect of subtle social cues or a lack of ability to accurately perceive and read social cues.

In addition, the negative affect and emotional regulation problems that often occur in children with LD are likely to deflect perceptions and interpretations of others' behaviors toward them. Moreover, the diagnostic model covers the following socio-emotional elements:

- The concept of self in children (is it negative?)

- Anxiety

- Depression

- Loneliness

- How does the child perceive:

$$
\begin{array}{ll}
\circ & \text { His intellectual abilities? } \\
\circ & \text { His school status? } \\
\circ & \text { His popularity }
\end{array}
$$

- Does the child have feelings of:

$$
\begin{array}{cl}
\circ & \text { Insecurity? } \\
\circ & \text { Inadequacy? } \\
\circ & \text { Guilt? } \\
\circ & \text { Impotence? } \\
\circ & \text { Vulnerability? }
\end{array}
$$

- Does the child change mood in a remarkable way?

- How does he react to changes?

\section{E. Sensory specifications:}

Children with learning disabilities often experience impaired color vision. As a result, many institutional situations require a soothing environment. An experiment at the University of Alberta proves the impact of environmental colors on the behavior and blood pressure of 14 children with disabilities. Hence, color psychology has a significant impact on the learning abilities and behavior of a child with LD. Failure in auditory processing is often cited as a major or contributing cause of language and learning disabilities in children. Some indicators of hearing loss:

- Distracted by noise

- It's hard to stay focused or to remember a verbal presentation

- Can misinterpret or have difficulty remembering oral instructions; difficulty following directions in a series

- Say "what?" Many, even when heard a lot of what was said

In addition, the impact of emotion on the learning process of the child with LD cannot be a negligible factor because

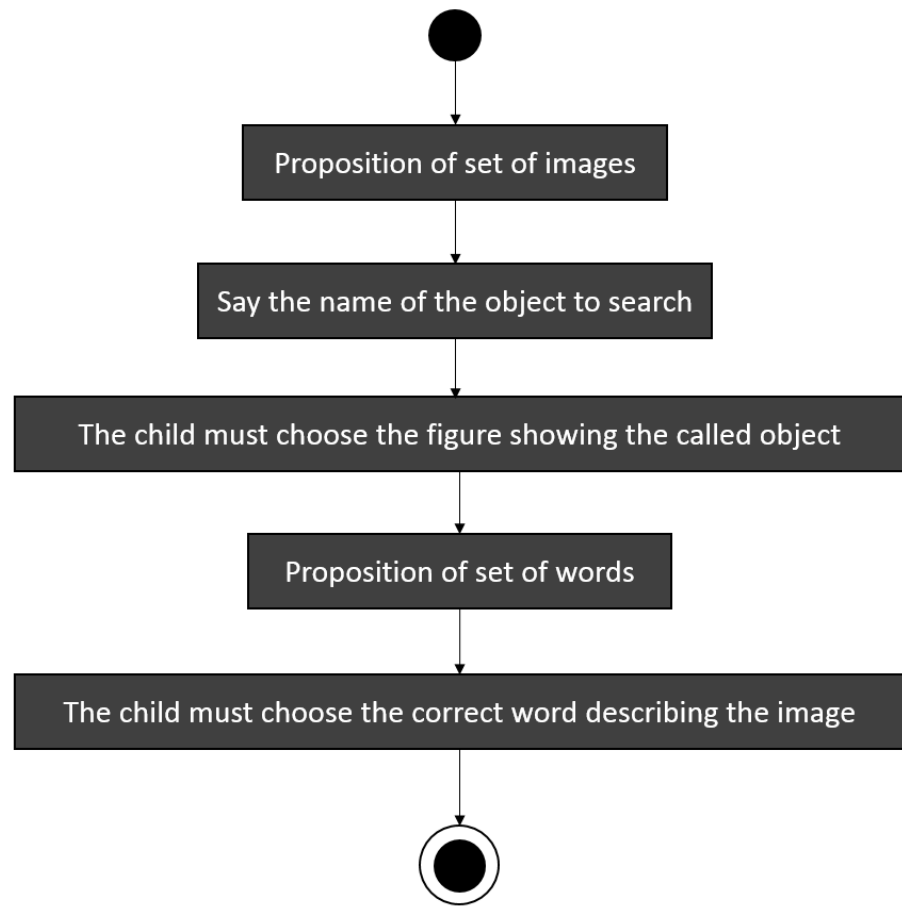

Fig. 6. Educational activity proposed by the pedagogue expert for a dyslexic child

emotion can play the role of leverage because it can be an obstacle to change. acquisition of a new knowledge. Strengthening the emotional state of the child and correcting the abnormalities that he / she experiences will help to improve his / her perception of learning and, as a result, promote learning.

\section{CASE STUdy: DYSLEXIA}

In this part, we develop all the deliverables of the KASP methodology for the case of a child with dyslexia disorder. Knowing that dyslexia is a lasting disorder of written language affecting reading, spelling and writing. These disorders are distinguished from a simple delay of acquisition, a mental retardation, a hearing problem, a visual problem, an emotional problem, a speech problem, bilingualism. The troubles persist in time, thats why we talk about lasting trouble.

The Case Study Diagnostic Worksheet contains the five specifications, indicating their severity and frequency on a scale of 0 to 3 as exposed in the Table. 1 :

TABLE I. SEVERITY AND FREQUENCY LEVELS

\begin{tabular}{|ll|}
\hline Severity & \\
& 0 does not exist \\
1 soft & 2 moderate \\
& 3 severe \\
\hline Frequency & \\
\hline & $\begin{array}{l}0 \text { never have the symptom } \\
1 \text { have the symptom from time to time } \\
2 \text { have the symptom often } \\
3 \text { have the symptom all the time }\end{array}$ \\
\hline
\end{tabular}

After having the diagnosis model worksheet presented in Table. 2, experts in cognition, pedagogy, hearing and vision intervene to develop the conceptual architecture. 


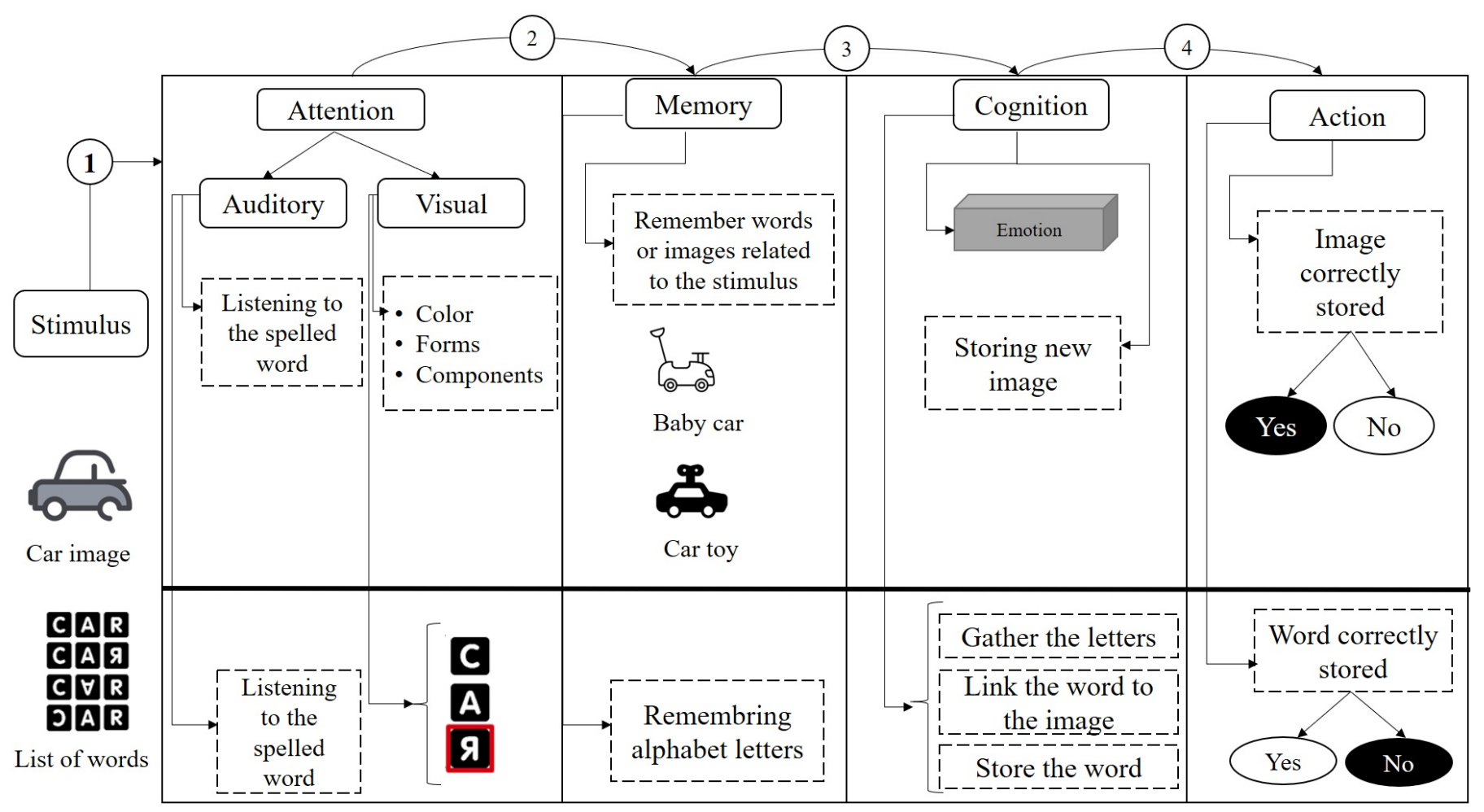

Fig. 7. Mental model of a dyslexic child

\section{Emotion}

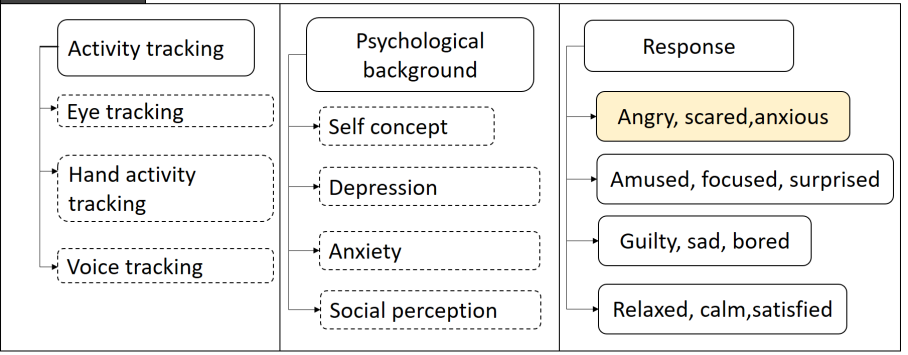

Fig. 8. Emotional Mental Model of a Dyslexic Child

The cognition expert analyzes the diagnostic model in order to build the mental models of the dyslexic child, the latter having a score of 3 at the level of severity of the writing deficit can be translated by a frequent permutation of letters during the writing. So the pedagogue expert proposes a game scenario to correct this deficit, the scenario is as illustrated in Fig. 6.

Here is an example of a mental model in Fig. 7 developed by the cognitive expert illustrating the deficit related to the pedagogy where the child permutes the letters, the mental model includes in itself the affective one because the emotion presents itself at the level of the cognitive treatment.

So the expert in child psychology studies the diagnostic record in order to build the emotional pattern of the child and it is presented in Fig. 8.

The proposed methodology is iterative trying to formalize a pragmatic and manageable approach, it helps to help
TABle II. Dyslexia Case Study Diagnostic Worksheet

\begin{tabular}{|lllll|}
\hline & Symptoms & Severity & Frequency & Notes \\
\hline Cognitive specifications & - Spatiotemporal deficit & 2 & 2 \\
& - Pedagogical deficit & & \\
& * Reading & 3 & 3 \\
& * Writing & 3 & 3 \\
Motor specifications & * Logic and reasoning & 2 & 1 \\
& - Motor coordination & 2 & 2 \\
& - Mulfunction of tactile inferences & 1 & 2 \\
Emotional specifications & - Uncontrolled manual movement & 1 & 2 \\
& & & \\
& - Bad self-concept & 3 & 3 \\
& - Depression & 1 & 1 \\
& - Anxiety & 2 & 2 \\
Behavioral specifications & - Social perception & 3 & 3 \\
& - Hyperactivity & 3 & 3 \\
& - Chronic pain & 1 & 2 \\
Sensory specifications & - Clownerie & 2 & 3 \\
& & & \\
& - Hearing impairment & 2 & 2 \\
\hline
\end{tabular}

children with learning disabilities to overcome these deficits by highlighting their emotional state that plays a key role in the process of learning. the child while integrating a playful environment generating entertainment.

\section{DISCUSSION}

Indeed, the methodology of designing serious learning games for the benefit of children with learning disabilities combines the conceptual and software processes, the novelty associated with this proposal lies in taking into consideration the emotional state of the child.

This can induce various emotional experiences in learners. Therefore, emotional influences need to be carefully 
considered in the design of educational courses in order to maximize learner engagement as well as improve learning and long-term retention of materials [29]. Numerous studies have reported that human cognitive processes are affected by emotions, including attention [30], learning and memory [31], reasoning [32] and problem solving [33]. Abrams [34] said,The vast majority of children with learning disabilities have an emotional problem associated with learning difficulty. Therefore, the proposed methodology gives the same level of importance to the knowledge as the emotion and it's a very robust approach because it implements the most rigorous teaching practices.

The KASP methodology proposes a design environment ensuring a good collaboration between the various stakeholders, including a well-detailed modeling of the pedagogical structure allowing a better choice of pedagogical activities.

Considering hearing, sight and kinesthetic parameters helps enabling better interactive communication between the learner and the proposed game scene.

Moreover its integration of the emotional factor favors a better regulation of the emotional state of the learner and it guarantees intrinsic motivation.

It begins by defining the needs of the target audience, in other words the type of disorder to be treated, then it goes on to the conception of the cognitive and affective mental models as well as the sensory specifications in order to propose the appropriate pedagogical scenarios.

The development of the prototypes, which will be tested and evaluated in the next step. And finally, the implementation of the game through the deployment of prototype results.

In fact, the deployed serious learning game, promoting the involvement of the player-learner and a good connection between educational and fun elements, respects the four dimensions:

- Fun: its about fun, the taste of competition, creating commitment to efficiency and productivity.

- Epistemic: Where knowledge is the object of the game

- Ergonomic: presenting seamless, easy to use, flexible and interactive interfaces

- Contextual: based on the objectives designated by the experts to meet the needs initially expressed

Contrariwise, the KASP methodology lacks some performance measures regarding the validity of the mental models of knowledge and emotions made by the experts. Moreover, it depends closely on the human experts because thanks to them that the raw material is elaborated for generating the educational scenarios.

\section{PERSPECTIVES AND Future WORK}

Serious learning games have shown great potential as an effective training methodology, but such a technique involves an extremely complex development process, with few guidelines available for effective evaluation.

The authors suggest using a fuzzy logic approach to establish an efficient evaluation of the KASP-based learning system, such as that proposed by El Alami and de Arriaga [35]. It is a fuzzy assessment of computing emotional and cognitive in intelligent e-learning systems that encompasses a set of fuzzy techniques acting on several levels especially the cycle of methodology as well as development and maintenance of the system designed.

\section{Conclusion}

In conclusion, the design of a serious learning game that helps children with LD in their learning curriculum is the subject of this article. Having a diagnostic model specifying the key parameters to identify the type of disorder is therefore a crucial step that obviously precedes the game design process.

In addition, exploiting the potential of gamification to improve learner engagement and increase motivation is the central idea of this article. Furthermore, understanding the emotion of the learner having a LD throughout the learning process through the techniques of affective computing will help to correct imperfections not only at the knowledge level but also at the socio-emotional level.

\section{REFERENCES}

[1] D. Michael and D. Chen, Serious games, Mason, Ohio: Course Technology, p.17, 2011

[2] J. Alvarez, D .Djaouti and O. Rampnoux, Introduction au serious game, 2nd ed. Paris: Questions thoriques, 2012.

[3] I. Marfisi-Schottman, S. George and F. Tarpin-Bernard, Tools and Methods for Efficiently Designing Serious Games, In: 4th Europeen Conference on Games Based Learning ECGBL, 2010

[4] M. Immordino-Yang and A. Damasio, We Feel, Therefore We Learn: The Relevance of Affective and Social Neuroscience to Education, Mind, Brain, and Education, 1(1), pp.3-10, 2007

[5] P. Schutz, J. Hong, D. Cross and J. Osbon, Reflections on Investigating Emotion in Educational Activity Settings, Educational Psychology Review, 18(4), pp.343-360, 2006

[6] T. Hascher, Learning and Emotion: Perspectives for Theory and Research, European Educational Research Journal, 9(1), pp.13-28, 2010

[7] L. Gaussot, Le jeu de l'enfant et la construction sociale de la ralit, Le Carnet PSY, 62(2), p.22, 2001

[8] K. Hirsh-Pasek and R. Michnick Golinkoff, Play - Why Play = Learning - Encyclopedia on Early Childhood Development Available at: http://www.child-encyclopedia.com/play/according-experts/why-playlearning, 2008

[9] A. Abdul Jabbar and P. Felicia, Gameplay Engagement and Learning in Game-Based Learning, Review of Educational Research, 85(4), pp.740779,2015

[10] C. Abt, Serious games, Lanham: University Press of America, 1987

[11] S. Egenfeldt-Nielsen, B. Meyer and B. Srensen, Serious Games in Education, Santa Barbara: Aarhus University Press, 2011

[12] K. Salen and E. Zimmerman, Rules of play, Johanneshov: TPB, 2011

[13] T. Lloyd Buck, Living the Case Study: Teaching Management and Leadership Ethics Online Through Serious Games, In: Society for the Advancement of Information Systems, 2014

[14] G. Paquette, F. Crevier and C. Aubin, Mthode d'ingnierie d'un systme d'apprentissage (MISA), Revue informations in Cognito, 8, 1997

[15] V. Lavergne Boudier and Y. Dambach, Serious game, Paris: Hermes Science, 2010

[16] M. Mcmahon, The DODDEL Model, Games-Based Learning Advancements for Multi-Sensory Human Computer Interfaces, 98-118, 2009

[17] J.W. Keefe, Learning style: An overview, NASSP's Student learning styles: Diagnosing and proscribing programs (pp. 1-17). Reston, VA. National Association of Secondary School Principles, 1979 
[18] K. Rapeepisarn, K.W. Wong, C.C. Fung and M.S. Khine, The Relationship between Game Genres, Learning Techniques and Learning Styles in Educational Computer Games, Technologies for E-Learning and Digital Entertainment Lecture Notes in Computer Science, 497-508, 2008

[19] M. El Alami, N. Tahiri and F. de Arriaga, DIAUTIS: A Fuzzy and Affective Multi-agent Platform for the Diagnosis of Autism, British Journal of Applied Science \& Technology, 21(4), 1-28, 2017

[20] S.S. Haykin, Neural networks and learning machines, Delhi: Pearson, 2016

[21] J.F. Sowa, Semantic Networks, In Encyclopedia of Cognitive Science, L. Nadel (Ed.), 2006

[22] R.W. Picard, Affective computing, Cambridge, MA: MIT Press, 2000

[23] S. Gano-Phillips, Affective learning in general education, Special Topic: Assessment in University General Education Program 6(1), 144, 2009

[24] F. de Arriaga, A. Arriaga and M. El Alami, Intelligent E-Learning Systems: Affective and Cognitive Computing, In C. Montgomerie \& J. Seale (Eds.), Proceedings of ED-MEDIA 2007-World Conference on Educational Multimedia, Hypermedia \& Telecommunications (pp 1127-1137). Vancouver, Canada: Association for the Advancement of Computing in Education (AACE), 2007

[25] R. Felder and L. Silverman, Learning and teaching styles in engineering education, Journal of Engineering Education, 78, 7, 674-681, 1988

[26] A.Y. Kolb and D.A. Kolb, Learning Styles and Learning Spaces: Enhancing Experiential Learning in Higher Education, Academy of Management Learning \& Education, 4(2), 193-212, 2005

[27] A. Ugena, F. de Arriaga and M. El Alami, Neural Network Ar- chitectures: New Strategies For Real Time Problems, Computing and Information Technologies, 2001

[28] H. Simon, Neural networks: A comprehensive foundation, New Delhi: Prentice-Hall of India, 2008

[29] L. Shen, M. Wang and R. Shen, Affective e-Learning: Using "Emotional" Data to Improve Learning in Pervasive Learning Environment, Educational Technology \& Society, 12 (2), 176189, 2009

[30] P. Vuilleumier, How brains beware: Neural mechanisms of emotional attention, Trends in Cognitive Sciences, 9(12), 585-594, 2005

[31] E.A. Phelps, Human emotion and memory: Interactions of the amygdala and hippocampal complex, Current Opinion in Neurobiology, 14(2), 198202, 2004

[32] N. Jung, C. Wranke, K. Hamburger and M. Knauff, How emotions affect logical reasoning: Evidence from experiments with mood-manipulated participants, spider phobics, and people with exam anxiety, Frontiers in Psychology, 5, 2014

[33] A. Isen, K. Daubman and G. Nowicki, Positive affect facilitates creative problem solving, Journal of Personality and Social Psychology, 52(6), pp.1122-1131, 1987

[34] J.C. Abrams, On Learning Disabilities: Affective Considerations, Journal of Reading, Writing, and Learning Disabilities International, 2(3), 189-196, 1986

[35] M. El Alami and F. de Arriaga, Fuzzy Assessment for Affective and Cognitive Computing in Intelligent E-learning Systems, International Journal of Computer Applications, 100(10), 40-46, 2014 